Agriprimatech

Vol. 4 No. 2, April 2021

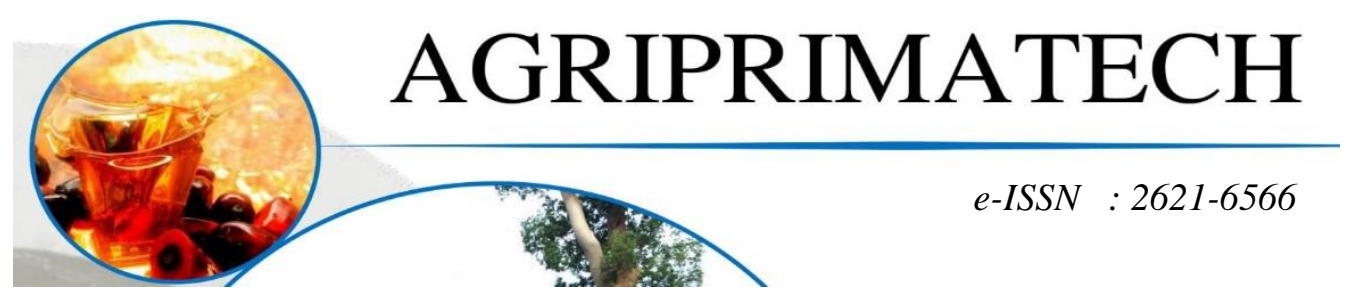

\title{
ANALISIS PENGARUH BIAYA PEMUPUKAN TANAMAN DAN BIAYA PANEN TERHADAP PENDAPATAN PETANI
}

\author{
(Studi Kasus Pada Petani Kelapa Sawit di Kecamatan Kuala Kabupaten \\ Langkat) \\ SAPRIDA ${ }^{1}$, WILSON SARUKSUK ${ }^{2}$ \\ 1,2, Fakultas Agro Teknologi, Jurusan Agribisnis, Universitas Prima Indonesia \\ Email : safrida_sgt@yahoo.com
}

\begin{abstract}
ABSTRAK
Tujuan penelitian ini adalah Untuk mengetahui pengaruh biaya pemupukan tanaman terhadap pendapatan petani, dan Untuk mengetahui pengaruh biaya panen terhadap pendapatan petani. Pengambilan sampel dilakukan kepada petani kelapa sawit dengan sampel sebanyak 100 responden. Metode analisis yang dilakukan adalah dengan metode analisis regresi linear berganda, pengelolahan data dibantu oleh sofware (SPSS) Versi 25. Penelitian ini dilakukan pada bulan Agustus-September 2020. Hasil penelitian ini disimpulkan bahwa 1). Usia yang paling banyak memiliki kebun kepala sawit yaitu usia 41-50 tahun, 2). Jenis kelamin yang paling dominan yaitu laki-laki sebesar $73 \%$, 3). Petani juga mulai bertani $>6$ tahun sebesar 62\%, 4). Dan luas lahan yang di miliki petani kelapa sawit rakyat yaitu sebesar 4 - 6 ha sebanyak 63\%, 5). Status lahan yang dikelola petani kelapa sawit adalah lahan sewa sebayak $51 \%$.
\end{abstract}

Kata Kunci: Petani, Kelapa Sawit, Rakyat , Analisis, Regresi.

\section{PENDAHULUAN}

Pemupukan merupakan faktor yang sangat penting untuk meningkatkan produksi. Biaya yang dikeluarkan untuk pemupukan berkisar antara 40- 60\% dari biaya pemeliharaan tanaman secara keseluruhan atau sekitar $24 \%$ dari total biaya produksi. Pemupukan pada tanaman kelapa sawit harus dapat menjamin pertumbuhan vegetatif dan generatif yang normal sehingga dapat memberikan produksi Tandan Buah Segar (TBS) yang optimal serta menghasilkan minyak sawit mentah yang tinggi baik kualitas maupun kuantitas (Adiwiganda, 2007).

Efektivitas

pemupukan berhubungan dengan persentase hara pupuk yang diserap tanaman. Pemupukan dikatakan efektif jika sebagian besar hara 
Agriprimatech

Vol. 4 No. 2, April 2021

pupuk diserap tanaman sedangkan efisiensi pemupukan berkaitan dengan hubungan antara biaya (bahan pupuk, alat kerja, dan upah) dengan tingkat produksi yang dihasilkan. Agar kebutuhan tanaman atas unsur hara dapat tercukupi dengan tepat maka sebelum diadakan pemupukan terlebih dahulu perlu analisis kebutuhan unsur hara tanaman tersebut melalui analisis tanah dan daun (Pahan 2008).

Pasca panen diartikan sebagai berbagai tindakan atau perlakuan yang diberikan pada hasil pertanian setelah panen sampai komoditas berada di tangan konsumen. Istilah tersebut secara keilmuan lebih tepat disebut pasca produksi (postproduction) yang dapat dibagi dalam dua bagian atau tahapan, yaitu pasca panen (postharvest) dan pengolahan (processing). Biaya panen (postharvest) sering disebut juga sebagai pengolahan primer (primary processing) merupakan istilah yang digunakan untuk semua perlakuan dari mulai panen sampai komoditas dapat dikonsumsi "segar" atau untuk persiapan pengolahan berikutnya. Umumnya perlakuan tersebut tidak mengubah bentuk penampilan atau penampakan, kedalamnya termasuk berbagai aspek dari pemasaran dan distribusi. Pengolahan (secondary processing) merupakan tindakan yang mengubah hasil tanaman ke kondisi lain atau bentuk lain dengan tujuan dapat tahan lebih lama (pengawetan), mencegah perubahan yang tidak dikehendaki atau untuk penggunaan lain.

\section{Metode Penelitian}

\section{Lokasi dan Waktu Penelitian}

Lokasi dilakukannya penelitian di Kecamatan Kuala, Kabupaten Langkat. dilaksanakan pada bulan AgustusSeptember tahun 2020.

\section{Jenis dan Sumber Data}

Data yang dikumpulkan dalam penelitian ini terdiri dari data primer

$$
\text { e-ISSN : 2621-6566 }
$$

dan data sekunder. Data primer adalah data yang diperoleh secara langsung dari sumber informasi dengan menggunakan instrumen kuisioner dan wawancara terhadap petani. Sedangkan data sekunder diperoleh secara tidak langsung melalui pihak ketiga seperti internet dan instansi lain yang terkait.

\section{Metode Pengumpulan Data}

Metode pengumpulan data yang digunakan dalam penelitian ini adalah teknik wawancara dan teknik angket (kuisioner). Teknik angket merupakan metode pengumpulan data yang dilakukan untuk mengumpulkan data dengan cara membagi daftar pertanyaan kepada responden agar responden tersebut memberikan jawabannya. Kuisioner dalam penelitian ini merupakan kuisioner tertutup. Teknik wawancara dilakukan dengan mewawancarai langsung sebagian besar konsumen yang mengisi kuisioner.

\section{Metode Pengolahan Data}

Pengolahan data dilakukan dengan menggunakan Microsoft Excel 2007 dan SPSS VERSI 25.

Adapun metode pengolahan data karakteristik responden dan proses pengambilan keputusan sebagai berikut:

1. Melakukan pengumpulan data dengan menggunakan kuisioner dan wawancara.

2. Merekap jawaban responden dengan software Microsoft Excel 2007.

3. Menghitung persentase jawaban responden.

Menganalisis persentase jawaban responden.

\section{Analisis Regresi Berganda}

Populasi penelitian adalah
konsumen petani kelapa sawit di


Agriprimatech

Vol. 4 No. 2, April 2021

Kecamatan Kuala Kabupaten Langkat adalah sejumlah 42.119 penduduk yang mempunyai perkebunan kelapa sawit rakyat. Metode penentuan besar sampel pada penelitian ini adalah dengan menggunakan metode slovin, dengan persamaan sebagai berikut (Supriana, 2016):

$$
n=\frac{\mathrm{N}}{1+€^{2} \cdot \mathrm{N}}
$$

Dimana: $\mathrm{n}=$ Besar sampel $\mathrm{N}=$ Besar populasi

$\epsilon=$ Batas toleransi kesalahan (error tolerance) $10 \%$. Maka besar sampel yang akan diteliti adalah:

$$
\begin{aligned}
& n=\frac{42 \cdot 119}{1+0,1^{2} \cdot 42 \cdot 119} \\
& =99,9 \text { sampel }
\end{aligned}
$$

Metode penentuan sampel yang digunakan adalah proportional random sampling. Menurut Ridwan (2010), "proportional Random

$$
\text { e-ISSN :2621-6566 }
$$

Sampling" (sampling pertimbangan) ialah teknik sampling yang digunakan peneliti jika peneliti mempunyai pertimbanganpertimbangan tertentu dalam pertimbangan sampelnya untuk tujuan tertentu". Setelah menggunakan teknik sampling, peneliti menentukan sampel yang akan digunakan. Sampel menurut Sugiyono (2012), adalah "Bagian dari jumlah dan karakteristik yang dimiliki oleh populasi".

\section{HASIL DAN PEMBAHASAN}

\section{Karakteristik Responden}

Karakteristik responden digunakan untuk mengetahui keragaman dari responden berdasarkan Jenis Kelamin, Usia, Mulai Bertani, Luas Lahan, Status Lahan. Hal ini diharapkan dapat memberikan gambaran yang cukup jelas mengenai kondisi dari responden dan kaitannya dengan masalah dan tujuan penelitian tersebut. Keragaman responden dapat ditunjukkan pada Tabel 1 berikut ini:

Tabel 1. Karakteristik Responden

\begin{tabular}{|c|c|c|}
\hline Berdasarkan & Kategori & Jumlah \\
\hline \multirow{2}{*}{ Jenis Kelamin } & Laki-Laki & 73 \\
\cline { 2 - 3 } & Perempuan & 27 \\
\hline \multirow{2}{*}{ Usia } & $30-40$ Tahun & 6 \\
\cline { 2 - 3 } & 41-50 Tahun & 36 \\
\cline { 2 - 3 } & 51-60 Tahun & 33 \\
\hline
\end{tabular}


Agriprimatech

Vol. 4 No. 2, April 2021

e-ISSN :2621-6566

\begin{tabular}{|c|c|c|}
\hline \multirow{4}{*}{ Tingkat Pendidikan } & SMP & 7 \\
\hline & SMA & 60 \\
\hline & Diploma & 20 \\
\hline & S1 & 13 \\
\hline \multirow{3}{*}{ Mulai Bertani } & 2-4 Tahun & 2 \\
\hline & 4-6 Tahun & 36 \\
\hline & $>6$ Tahun & 62 \\
\hline \multirow{3}{*}{ Luas Lahan } & $<4 \mathrm{Ha}$ & 65 \\
\hline & 4-6 Ha & 35 \\
\hline & $>6 \mathrm{Ha}$ & 0 \\
\hline \multirow{2}{*}{ Status Lahan } & Sewa & 51 \\
\hline & Milik Sendiri & 49 \\
\hline
\end{tabular}

Berdasarkan tabel 1, dapat diketahui bahwa dominan responden berdasarkan jenis kelamin adalah laki-laki yaitu 73 orang atau 73\%. Responden berdasarkan usia dominasi oleh responden dengan usia 4150 tahun yaitu sebanyak 46 orang atau $46 \%$. Responden berdasarkan tingkat pendidikan dominasi oleh responden SMA yaitu sebanyak 60 orang atau $60 \%$. Responden berdasarkan mulai bertani didominasi oleh responden yang memulai bertani $>6$ tahun yaitu sebanyak 62 orang Tabel 2. Uji Validitas atau $62 \%$. Responden berdasarkan luas lahan didominasi oleh responden yang mengelola lahan < $4 \mathrm{Ha}$ yaitu sebanyak 65 orang atau $65 \%$ dan responden berdasarkan status lahan didominasi oleh responden dengan status lahan sewa sebanyak 51 orang atau $51 \%$.

\begin{tabular}{|c|c|c|c|}
\hline Indikator Pertanyaan & R Hitung & Batas Valid & Keterangan \\
\hline X1_1 & 0,964 & 0,361 & Valid \\
\hline X1_2 & 0,964 & 0,361 & Valid \\
\hline X1_3 & 0,964 & 0,361 & Valid \\
\hline X1_4 & 0,985 & 0,361 & Valid \\
\hline X2 & 0,964 & 0,361 & Valid \\
\hline
\end{tabular}


Agriprimatech

Vol. 4 No. 2, April 2021

e-ISSN :2621-6566

\begin{tabular}{|c|c|c|c|}
\hline $\mathrm{Y}$ & 0,993 & 0,361 & Valid \\
\hline
\end{tabular}

Suatu pertanyaan dikatakan valid diketahui bahwa seluruh pertanyaan apabila $R$ hitung $>0,361$ ( $R$ tabel). dikatakan valid. Berdasarkan hasil uji validitas di atas, Tabel 3. Uji Reliabilitas

\begin{tabular}{|c|c|c|c|}
\hline Variabel & Cronbach's Alpha & Batas Reliabel & Keterangan \\
\hline Biaya Pemupukan (X1) & 0,863 & 0,6 & Reliabel \\
\hline Biaya Panen (X2) & 0,897 & 0,6 & Reliabel \\
\hline Pendapatan Petani (Y) & 0,608 & 0,6 & Reliabel \\
\hline
\end{tabular}

Pada tabel diatas, menunjukkan nilai Cronbach alpha $>0,6$ yang berarti pertanyaan dalam kuesioner sudah reliabel.

\section{Tabel 4. Uji Normalitas}

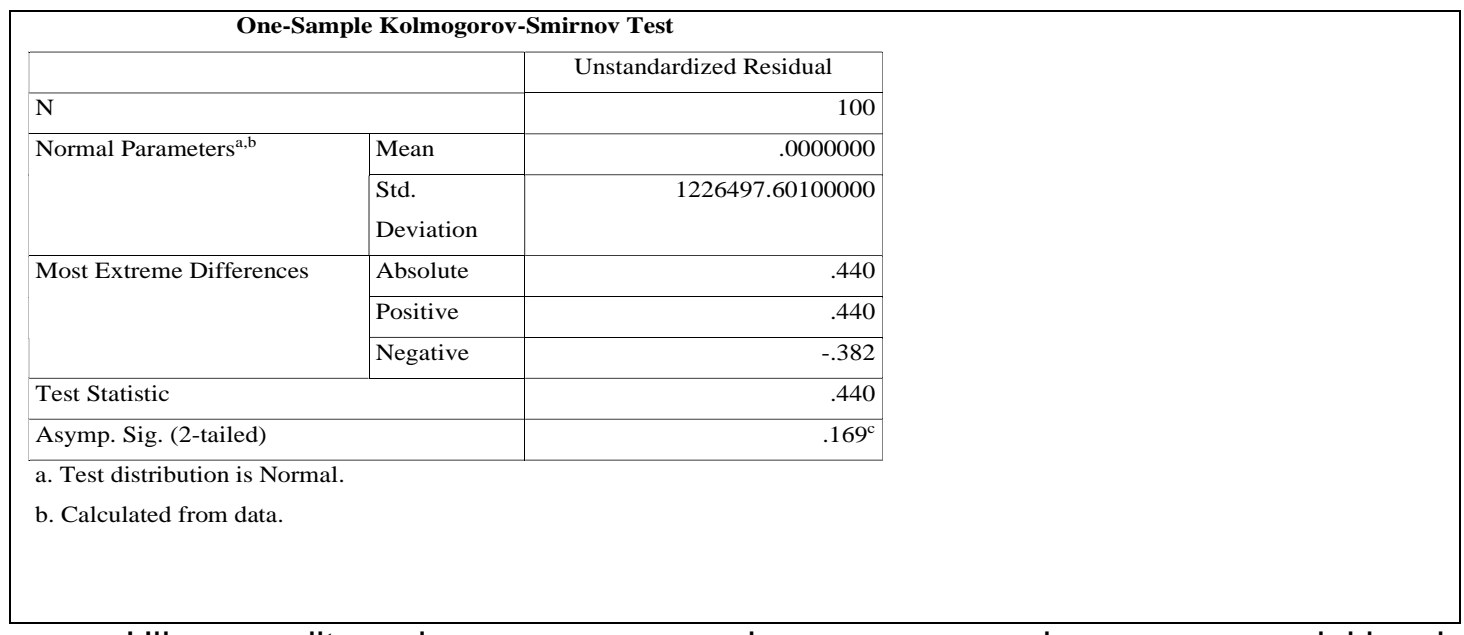

Uji normalitas dengan one samplekolmogorov diperoleh signifikan sebesar 0,169 $>0,05$. Dari hasil tersebut dapat disimpulkan bahwa data berdistribusi normal.

Hasil pengujian normalitas dengan $P$ menyebar di sekitas garis diagonal dan mengikuti garis arah diagonal. Maka persyaratan uji normalitas sudah terpenuhi. Hal ini dapat dilihat di gambar berikut.

Plot terhadap data penelitian dapat dilihat pada 
Agriprimatech

Vol. 4 No. 2, April 2021

e-ISSN : 2621-6566

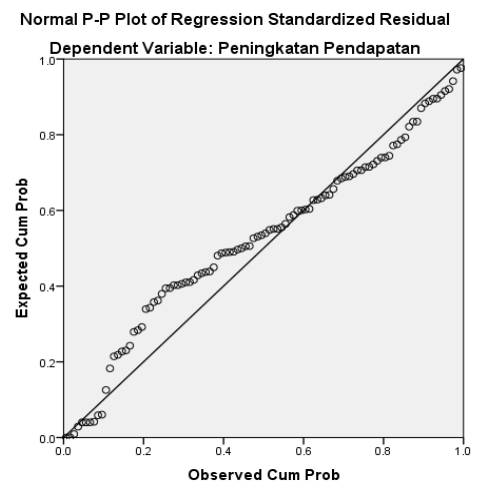

Tabel 5. Uji Multikolinearitas

\begin{tabular}{|c|c|c|c|c|c|c|}
\hline \multicolumn{7}{|c|}{ Coefficients $^{\mathrm{a}}$} \\
\hline \multirow{2}{*}{\multicolumn{2}{|c|}{ Model }} & \multicolumn{2}{|c|}{ Unstandardized Coefficients } & \multirow{2}{*}{$\begin{array}{c}\text { Standardized } \\
\text { Coefficients } \\
\text { Beta }\end{array}$} & \multicolumn{2}{|c|}{$\begin{array}{c}\text { Collinearity } \\
\text { Statistics }\end{array}$} \\
\hline & & B & Std. Error & & Tolerance & VIF \\
\hline \multirow[t]{3}{*}{1} & (Constant) & 12470946.750 & 1844989.362 & & & \\
\hline & $\begin{array}{l}\text { Biaya } \\
\text { Pemupukan }\end{array}$ & 9.227 & .691 & 4.283 & .497 & 2.114 \\
\hline & $\begin{array}{l}\text { Biaya } \\
\text { Panen }\end{array}$ & -46.745 & 4.481 & -3.346 & .497 & 2.114 \\
\hline
\end{tabular}

a. Dependent Variable: Peningkatan Pendapatan

Berdasarkan

hasil

uji untuk masing-masing variabel mempunyai nilai < 10 maka tidak terdapat persoalan multikolinearitas.

multikolinearitas dapat diketahui bahwa VIF

Tabel 6. Uji Autokorelasi Dengan Uji Durbin-Watson

Model Summary ${ }^{b}$

\begin{tabular}{|l|r|r|r|r|r|}
\hline Model & R & R Square & $\begin{array}{c}\text { Adjusted R } \\
\text { Square }\end{array}$ & $\begin{array}{l}\text { Std. Error of } \\
\text { the Estimate }\end{array}$ & $\begin{array}{l}\text { Durbin- } \\
\text { Watson }\end{array}$ \\
\hline 1 & $.975^{\mathrm{a}}$ & .950 & .949 & 1239077.393 & 1.692 \\
\hline
\end{tabular}

a. Predictors: (Constant), Biaya Panen, Biaya Pemupukallilai statistic durbin-watson adalah 1,692. Perhatikan bahwa nilai statistic b. Dependent Variable: Peningkatan Pendapatandurbin Watson terletak diantara 1 dan 3 , 
Agriprimatech

Vol. 4 No. 2, April 2021

e-ISSN : 2621-6566

maka asumsi non-Autokorelasi terpenuhi.

Dengan kata lain tidak terjadi Autokorelasi

Tabel 7. Uji Heteroskedastisitas dengan Uji Glejser

\section{Coefficients $^{\mathrm{a}}$}

\begin{tabular}{|l|l|r|r|r|r|r|}
\hline \multicolumn{2}{|l|}{} & \multicolumn{2}{|c|}{ Unstandardized Coefficients } & $\begin{array}{c}\text { Standardized } \\
\text { Coefficients }\end{array}$ & & \\
\cline { 2 - 8 } \multicolumn{2}{|l|}{ Model } & B & Std. Error & Beta & \multirow{2}{*}{ Sig. } \\
\hline 1 & (Constant) & -13864110.120 & 398195.654 & & -3.817 & .128 \\
\cline { 2 - 8 } & Biaya Pemupukan & -3.812 & .149 & -8.327 & -2.563 & .694 \\
\cline { 2 - 8 } & Biaya Panen & 26.962 & .967 & 9.082 & 2.882 & .415 \\
\hline
\end{tabular}

a. Dependent Variable: Abs_RES

Berdasarkan tabel di atas, diketahui nilai signifikan Biaya Pemupukan (X1) adalah 0,694 dan Biaya Panen (X2) adalah 0,415 . Karena nilai signifikansi kedua variabel di atas $>0,05$ maka sesuai dengan dasar pengambilan keputusan dalam uji glejser, dapat disimpulkan bahwa tidak terjadi gejala heteroskedastisitas dalam model regresi.

Tabel 8. Hasil Uji Biaya Pemupukan dan Biaya Panen Terhadap Pendapatan Petani Coefficients $^{\mathrm{a}}$

\begin{tabular}{|l|l|r|r|r|}
\hline \multicolumn{2}{|c|}{} & \multicolumn{2}{|c|}{ Unstandardized Coefficients } & $\begin{array}{c}\text { Standardized } \\
\text { Coefficients }\end{array}$ \\
\cline { 3 - 5 } Model & \multicolumn{1}{|c|}{ B } & Std. Error & Beta \\
\hline 1 & (Constant) & 12470946.750 & 1844989.362 & \\
\cline { 3 - 5 } & Biaya Pemupukan & 9.227 & .691 & 4.283 \\
\cline { 3 - 5 } & Biaya Panen & -46.745 & 4.481 & -3.346 \\
\hline
\end{tabular}

a. Dependent Variable: Peningkatan Pendapatan 
Agriprimatech

Vol. 4 No. 2, April 2021

e-ISSN : 2621-6566

Berdasarkan tabel di atas, dapat diketahui hasil analisis regresi diperoleh koefisien regresi yaitu variabel $X 1$ sebesar 9,227, dan X2 sebesar -46,745. Sehingga model persamaan regresi sebagai berikut:

$\mathrm{Y}=9,227 \mathrm{X} 1-46,745 \mathrm{X} 2+\mathrm{e}$

Keterangan:

$\mathrm{Y} \quad=$ peningkatan pendapatan

$\mathrm{X} 1=$ Biaya Pemupukan

$\mathrm{X} 2=$ Biaya Panen

e $\quad=$ error sampling

Berdasarkan persamaan regresi diatas mengenai variabel yang mempengaruhi peningkatan pendapatan maka dijelaskan sebagai berikut:

- Koefisien regresi biaya pemupukan sebesar 9,227 artinya jika nilai biaya pemukukan meningkat satu poin, berarti akan meningkatkan pendapatan sebesar 9,227 kali.

- Koefisien regresi biaya panen sebesar 46,745 artinya jika nilai biaya panen meningkat satu poin, berarti akan menurunkan pendapatan sebesar 46,745 kali.

Tabel 9. Koefisien Determinasi $\left(\mathbf{R}^{2}\right)$

Model Summary ${ }^{b}$

\begin{tabular}{|l|r|r|r|r|r|}
\hline Model & R & R Square & $\begin{array}{c}\text { Adjusted R } \\
\text { Square }\end{array}$ & $\begin{array}{l}\text { Std. Error of } \\
\text { the Estimate }\end{array}$ & $\begin{array}{l}\text { Durbin- } \\
\text { Watson }\end{array}$ \\
\hline 1 & $.975^{\mathrm{a}}$ & .950 & .949 & 1239077.393 & 1.692 \\
\hline
\end{tabular}

a. Predictors: (Constant), Biaya Panen, Biaya Penpetark zalam melihat biaya pemupukan

b. Dependent Variable: Peningkatan Pendapatandan biaya panen sebanyak 95,0\%

Berdasarkan tabel diatas dapat

dilihat nilai $R$ square sebesar 0,950 atau

$95,0 \%$. Ini berarti peningkatan pendapatan dipengaruhi oleh biaya pemupukan dan biaya panen dan sisanya $5,0 \%$ dipengaruhi oleh faktor lain.

\section{Tabel 10. Uji Simultan (Uji F)}

ANOVA ${ }^{a}$

\begin{tabular}{|l|l|r|r|r|r|r|}
\hline \multicolumn{2}{|l|}{ Model } & Sum of Squares & df & Mean Square & F & Sig. \\
\hline 1 & Regression & $\begin{array}{r}283818518300000 \\
0.000\end{array}$ & 2 & 1419092592000000. & 924.30 & $.000^{\mathrm{b}}$ \\
& & & & & 000 & \\
& Residual & 148925340100000 & 97 & 1535312785000.000 & & \\
& .000 & & & & \\
\hline
\end{tabular}


Agriprimatech

Vol. 4 No. 2, April 2021

e-ISSN :2621-6566

\begin{tabular}{|l|l|r|r|r|r|r|}
\hline & Total & $\begin{array}{r}298711052300000 \\
0.000\end{array}$ & 99 & & & \\
& & & & & \\
\hline
\end{tabular}

a. Dependent Variable: Peningkatan Pendapata 0,05 ini menunjukkan bahwa model

b. Predictors: (Constant), Biaya Panen, Biaya Persamaan regresi berganda tersebut tepat

Berdasarkan hasil uji statistik penelitian dan dibandingkan dengan nilai $\mathrm{F}$ tabel didapatkan probalibilitas $=2,47$. Berdasarkan uji $\mathrm{F}$ diperoleh nilai Fhitung $=$ $924,302>2,47$ dan nilai signifikan $=0,000$ pengaruh peningkatan pendapatan yang terdiri dari biaya pemupukan dan biaya panen. Kesimpulannya biaya pemupukan dan biaya panen berpengaruh secara simultan terhadap peningkatan pendapatan.

\section{Tabel 11. Uji Parsial (Uji T)}

\section{Coefficients $^{\mathbf{a}}$}

\begin{tabular}{|c|c|c|c|c|c|c|}
\hline & & \multicolumn{2}{|c|}{ Unstandardized Coefficients } & \multirow{2}{*}{$\begin{array}{c}\text { Standardized } \\
\text { Coefficients } \\
\text { Beta }\end{array}$} & \multirow[b]{2}{*}{$\mathrm{t}$} & \multirow[b]{2}{*}{ Sig. } \\
\hline \multicolumn{2}{|c|}{ Model } & B & Std. Error & & & \\
\hline 1 & $\begin{array}{l}\text { (Const } \\
\text { ant) }\end{array}$ & 12470946.750 & 1844989.362 & & 6.759 & .000 \\
\hline & $\begin{array}{l}\text { Biaya } \\
\text { Pemup } \\
\text { ukan }\end{array}$ & 9.227 & .691 & 4.283 & 13.355 & .000 \\
\hline & $\begin{array}{l}\text { Biaya } \\
\text { Panen }\end{array}$ & -46.745 & 4.481 & -3.346 & $\begin{array}{r}- \\
10.433\end{array}$ & .000 \\
\hline
\end{tabular}

a. Dependent Variable: Peningkatan Pendapatanpemupukan dengan peningkatan

Berdasarkan hasil uji statistik penelitian dan dibandingkan dengan nilai $t$ tabel didapatkan probabilitas =1,985.

Variabel biaya pemupukan memiliki nilai t hitung 13,355 >1,985 dan sig. 0,000 $<0,05$ yang berarti terdapat pengaruh secara parsial dan signifikan antara biaya pendapatan.

Variabel biaya panen memiliki nilai $t$ hitung 10,433 > 1,985 dan sig. 0,000 <0,05 yang berarti terdapat pengaruh secara parsial dan signifikan antara biaya panen dengan peningkatan pendapatan. Panen berpengaruh positif terhadap pendapatan petani. 
Agriprimatech

Vol. 4 No. 2, April 2021

\section{Kesimpulan}

Berdasarkan hasil analisis dan pembahasan yang telah dilakukan dalam penelitian ini, telah disampaikan mengenai proses analisis data dan pengujian terhadap keenam hipotesis yang diajukan sesuai dengan justifikasi teoritis yang telah diuraikan, maka peneliti mengambil kesimpulan sebagai berikut.

1. Perceived Usefulness petani tidak berpengaruh signifikan terhadap Niat Beli.

2. Perceived Ease Of Use berpengaruh signifikan terhadap Niat Beli.

3. Subjective Norms berpengaruh signifikan terhadap Niat Beli.

4. Perceived Enjoyment berpengaruh signifikan terhadap Niat Beli.

5. Pengetahuan Produk tidak berpengaruh signifikan terhadap Niat Beli.

6. Persepsi Harga berpengaruh signifikan terhadap Niat Beli.

\section{DAFTAR PUSTAKA}

Adiutama, I Made Rendy Wicaksana dan I Wayan Santika 2013. Pengaruh persepsi kemudahan penggunaan, kegunaan yang dirasakan, dan tingkat pendidikan terhadap niat berbelanja kembali pada situs Tokobagus.com. (ojs.unud.ac.id). Diakses pada tanggal 25 Desember 2015

Ahmad dan Pambudi. (2014). Pengaruh persepsi manfaat, persepsi kemudahan, keamanan dan ketersediaan fitur terhadap minat nasabah dalam menggunakan internet banking (studi pada program layanan internet banking BRI). Jurnal Studi Manajemen, Vol 8, No 1, 2014.

Istiana., Laili. 2010. Pengaruh Sikap, Norma Subjektif dan Kontrol Keperilakuan Terhadap Niat Beli dan Perilaku beli

$$
\text { e-ISSN : 2621-6566 }
$$

Produk Susu Ultra High Temperature. Jurnal Fakultas Peternakan Universitas Gajahmada, Yogyakarta, Hal.507-512.

Karo Sekali, A., Afrianti, S., \& Trisnanda, N. (2020). Faktor-faktor Yang Mempengaruhi Adopsi Bibit Bersertifikat Pada Perkebunan Rakyat (Studi Pada Petani Kelapa Sawit di Kecamatan Bilah Hulu Kabupaten Labuhan Batu. Agriprimatech, 3(2), 62-73

Kusuma, Irma Dwi dan Untarini, Nindria. 2014. Pengaruh Pengetahuan Produk Terhadap Niat Beli Dengan Sikap Sebagai Variabel Intervening. Jurnal IImu Manajemen, 2(4):15731583

KISWANTO, J. HADIPURWANTA, dan B. WIJAYANTO. 2008. Teknologi Budidaya Kelapa Sawit. Balai Besar Pengkajian dan Pengembangan Teknologi Pertanian. Badan Penelitian dan Pengembangan Pertanian. $26 \mathrm{hlm}$.

Manullang, M., 2001, Manajemen Sumber Daya Manusia, Andi Offset, Yogyakarta.

Nawawi, H., 2001, Manajemen Sumber Daya Manusia. Gadjah Mada University Press, Jakarta.

Pahan, I., 2006. Panduan Lengkap Kelapa Sawit. Penebar Swadaya. Jakarta

Setiawan, Tommy dan Richard Andrew. 2012. Pengaruh Brand Image dan Product Knowledge terhadap Purchase Intention (Kasus: Kosmetik Merk "X"). Media Bisnis Trisakti School of Management,4(1):3444.

Siagian, S.P., 2004,. Teori Motivasi dan Aplikasinya, Rineka Cipta, Jakarta.

Swastha, Basu. Manajemen Penjualan. Edisi Ketiga. Yogyakarta : BPFE.

Trisnawati, Ella. Suroso, Agus. Dan Kumorohadi, Untung. 2012. Analisis faktor-faktor kunci dari niat pembelian kembali secara online 
Agriprimatech

Vol. 4 No. 2, April 2021

e-ISSN :2621-6566

(studi kasus pada konsumen fesh shop). Jurnal Bisnis dan Ekonomi.

Vol.19 No. 2 September 